\title{
Tangeretin inhibits IL-1 $\beta$ induced proliferation of rheumatoid synovial fibroblasts and the production of COX-2, PGE2 and MMPs via modulation of p38 MAPK/ERK/JNK pathways
}

\author{
Yong-Ji Li' ${ }^{1}$, Ting Zhang', Jian-Xin Tu' ${ }^{1}$, Gang $\mathrm{Li}^{\mathbf{2}}$ and Yan Zhou' \\ ${ }^{1}$ Department of Rheumatoid Immunology and ${ }^{2}$ Chemoradiation Oncology, The First Affiliated Hospital of Wenzhou \\ Medical University, Wenzhou, Zhejiang 325 000, China.
}

\begin{tabular}{|c|c|c|}
\hline \multicolumn{2}{|l|}{ Article Info } & Abstract \\
\hline$\overline{\operatorname{Rec}}$ & $4 \mathrm{~A}$ & ne study aimed to determine the effect of tangeretin in inhibiting the \\
\hline & 2 May 2 & terleukin-1 $\beta$ (IL-1 $\beta$ )-induced proliferation of RASFs and suppression of the \\
\hline line: & August 2 & production of inflammatory mediators. RASFs were isolated from synovial \\
\hline \multirow{5}{*}{\multicolumn{2}{|c|}{$\begin{array}{l}\text { Keywords: } \\
\text { Interleukin-1 } \beta \\
\text { Protein kinase } \\
\text { Rheumatoid arthritis } \\
\text { Tangeretin }\end{array}$}} & sue obtained from patients with RA during knee arthroscopy. The cells were \\
\hline & & posed to IL-1 $\beta(1.0 \mathrm{ng} / \mathrm{mL})$ and/ or tangeretin $(50$ or $100 \mu \mathrm{M})$. Cell viability \\
\hline & & s assessed following treatments. Expressions of MMPs and COX-2 were \\
\hline & & ed by real-time PCR and western blotting. Production of prostaglandin \\
\hline & & E2 (PGE2) by RASFs were analysed by ELISA. Expressions of mitogen \\
\hline & 5 & activated protein kinases (MAPKs) and nuclear factor-kB (NF-kB) were \\
\hline & 0 & ssessed by western blotting. Tangeretin significantly \\
\hline efs: & 48 & $\begin{array}{l}\text { proliferation of RASFs, as well as down-regulated the expression of MMP-1, } \\
\text { MMP-3 and COX-2 mRNA and protein and also the phosphorylation of ERK, } \\
\text { p38 and JNK. Raised level of expression of NF-KB and PGE2 induced by IL-1 }\end{array}$ \\
\hline \multicolumn{2}{|c|}{$\begin{array}{l}\text { Correspondence: GL YZ } \\
\text { e-mail: ligangtpm@yeah.net } \\
\text { zhouyan7703@gmail.com }\end{array}$} & $\begin{array}{l}\text { was reduced by tangeretin. Results indicate that tangeretin was effective in } \\
\text { inhibiting the synovial fibroblast proliferation, as well regulated MMPs, COX- } \\
\text { 2, PGE2 via modulation of p38 MAPK, ERK and JNK pathways. }\end{array}$ \\
\hline
\end{tabular}

\section{Introduction}

Rheumatoid arthritis (RA) is a chronic inflammatory systemic disease of unknown etiology. It is characterized by high infiltration of leukocytes into the synovium, leading to hyperplasia of the synovial lining, which causes progressive destruction of the cartilage consequently resulting in erosion of the underlying bone (Pope, 2002). The activated rheumatoid synovial fibroblasts (RASFs) aggressively participate in RA synovitis. RASFs in RA joints vigorously proliferate forming a pannus, which produce inflammatory mediators such as cytokines, matrix metalloproteinases (MMPs), and cyclooxygenase-2 (COX-2) eventually leading to the destruction of articular bone and cartilage (Cawston, 1995; Han et al., 2003).

Interleukin $1 \beta$ (IL-1 $\beta$ ) is considered as the most impor- tant cytokine in the pathogenesis of inflammatory events in RA. IL-1 $\beta$ induces the proliferation of RASFs and also causes the production of high levels of inflammatory mediators- MMPs and prostaglandin E2 (PGE2) (Choy and Panayi, 2001). While the pathogenesis of RA is not completely understood, the process is reported to involve cellular infiltration into the synovial tissue with marked increase of inflammatory cytokinestumor necrosis factor(TNF) $\alpha$, interleukin(IL)-1 $\beta$ and IL6 , that eventually contribute to cartilage and bone erosion (Arend, 2001; Choy, 2012). These mediators activate major signalling pathways such as the nuclear factor (NF)- $\mathrm{KB}$ and mitogen activated protein kinases (MAPKs) (Tas et al., 2005).

MAPKs are a family of serine/threonine kinases that are involved in various cellular events such as inflammation, transcription of pro-inflammatory factors and 
phosphorylation of transcription factor NF-kB ( $\mathrm{Su}$ and Karin, 1996; Dong et al., 2002). Further research have demonstrated the activation of the members of signalling cascades such as NF-kB p65, and extra cellular signal-regulated kinase (ERK), JunN-terminal kinase (JNK) and p38MAPKs in RA synovial tissue. Upon activation ERK, JNK and p38MAPK play vital roles in synovial inflammation and proliferation of synovial cells (Luo et al., 2010; Yang et al., 2010). Present day treatment strategies towards RA are targeted predominantly against inflammatory mediators. Owing to the adverse effects of the chronic usage of anti-inflammatory drugs in the treatment, exploring alternative means is indispensible.

Flavonoids are widely present in fruit and vegetables. Citrus flavonoids have a wide range of biological activities including anticarcinogenic and antitumor. Tangeretin $\left(5,6,7,8,4^{\prime}\right.$-pentamethoxy flavone) is present in oranges and in other citrus peels (Dong et al., 2014). It has been reported to exhibit various pharmacological activities: anti-oxidant (Chen et al., 2012), neuroprotective (Datla et al., 2001), anti-inflammatory activity (Ho and Kuo, 2014; Shu et al., 2014) and inhibition of cancer cell proliferation (Dong et al., 2014; Periyaswamy et al., 2015). Tangeretin has been reported to reduce the production of nitric oxide (NO) by inhibition of LPSinduced expression of nitric oxide synthase (iNOS) and COX-2 in microglial cells (Shu et al., 2014). Considering the biological activities of tangeretin, we investigated its effects in proliferation of rheumatoid synovial fibroblasts and production of chemokines by RASFs. Influence of tangeretin on various signal transduction pathways involved in inflammation were also evaluated.

\section{Materials and Methods}

Reagents and chemicals: Tangeretin was obtained from Sigma-Aldrich (St. Louis, MO, USA) and dissolved in DMSO with a concentration of $100 \mathrm{mM}$ stock solution. Fetal bovine serum (FBS) was obtained from Sigma-Aldrich (St. Louis, MO, USA). Recombinant human IL-1 $\beta$ was purchased from Cell Signaling Technology (Beverly, MD, USA). Antibodies against IkBa, NF-kB (p65), ERK, JNK, p38, p-ERK, p-JNK, $\mathrm{p}^{-\mathrm{p} 38,} \beta$-actin (Cell Signaling Technology (Beverly, MD, USA), MMP-1, MMP-3 and tissue inhibitors of metalloproteinases (TIMP), COX-2 (Santa Cruz Biotechnology, Inc., Santa Cruz, CA, USA) were used in Western blot analysis. All other chemicals used in the investigation were purchased from Sigma-Aldrich, (St. Louis, MO, USA) unless otherwise specified.

Isolation and culture of RASFs: This study was approved by the national university hospital ethical committee. Synovial tissues were obtained from patients at the total knee arthroplasty in accordance with the American College of Rheumatology Criteria for RA (Arnett et al.,
1998) and as previously described by Lee et al. (2006) and informed consent was obtained from all patients. Cells were incubated at $37^{\circ} \mathrm{C}$ in $5 \% \mathrm{CO}_{2}$ in RPMI 1640 medium supplemented with $10 \%$ (v/v) FBS, 100 units/ $\mathrm{mL}$ of penicillin, and $100 \mu \mathrm{g} / \mathrm{mL}$ of streptomycin. The RASFs were isolated after 3-7 passages. The synovial cells were homogeneous in morphology and had the manifestation of RASFs with distinctive fibroblastoid configuration. Purity of the cells were tested using phycoerythrin (PE)-conjugated anti-Thy-1 (CD90) or anti-CD14 and fluorescein isothiocyanate (FITC)conjugated anti-CD3 mAb (BD Pharmingen, San Diego, CA).

Determination of cell viability: Cell viability of the RASFs was determined using CCK-8 kit (Dojindo Laboratories, Japan). CCK-8 kit employs Dojindo's tetrazolium salt, WST-8 [2-(2-methoxy-4-nitrophenyl)-3-(4-nitrophenyl)5-(2,4-disulfophenyl)-2H-tetrazolium, monosodium salt] for determining viable cells. WST- 8 in the living cells is reduced by cellular dehydrogenases to an orange formazan product that is directly proportional to the viable cell counts. Briefly, RASFs ( $2 \times 10^{4}$ cells / well) were treated with various concentrations of tangeretin (50 and $100 \mu \mathrm{M})$ and incubated for 24 or $48 \mathrm{~h}$ with/without IL-1 $\beta$ (1.0 ng/mL). Following incubation, the cells were washed twice with PBS and CCK-8 (20 $\mu \mathrm{L}$ ) was added to each well and incubated for about 2-3 hours. Formazan crystals formed were dissolved by adding DMSO (100 $\mu \mathrm{L} /$ well). The absorbance was read at $450 \mathrm{~nm}$ using a microplate reader (Model 3550, BioRad, Richmond, CA, USA).

Analysis of apoptosis by annexin $V$ assay: Following incubation with tangeretin with/without IL-1 1 (1.0 ng/ $\mathrm{mL}$ ) for 24 and 48 hours, cells were then trypsinized and collected for detection of apoptosis with annexin V-FITC Apoptosis Detection kit (Santa Cruz Biotechnology, Santa Cruz, CA, USA) according to the manufacturer's instructions. Briefly, $1 \times 10^{6}$ cells that were pretreated with tangeretin were subjected to annexin $\mathrm{V}$ staining. The treated cells were washed in PBS, resuspended in $100 \mu \mathrm{L}$ of binding buffer containing a FITC-conjugated anti-annexin V antibody. The cells were then analyzed for flurosence using a flow cytometer (FACS Calibur, BD Biosciences).

RNA isolation and semi-quantitative RT-PCR: To evaluate the expression of MMP-1, MMP-3, TIMP-1 and COX-2 mRNA, RASFs $\left(1 \times 10^{6}\right.$ cells $)$ were cultured for 12,24 or 48 hours with/without IL-1 $\beta$ (1.0 ng/mL) and/or tangeretin (50 or $100 \mu \mathrm{M})$. Total RNA was extracted from cultured RASFs after incubation with tangeretin using TRIsol reagent (Invitrogen, Carlsbad, CA, USA) following the manufacturer's instructions. cDNA derived from the reverse transcription of RNA using Maxime RT Premix Kit (iNtRON Biotechnology, South Korea) was amplified using the following primer sets: TIMP-1 (forward) 5'-CCT TCT GCA ATT CCG ACC 
TCG TC-3' (reverse) 5'-CGG GCA GGA TTC AGG CTATCT GG-3', MMP-1 (forward) 5'-GAA GGA GAT GAA GCA GCC CAG ATG T-3' (reverse) 5'-CAG TTG TGG CCA GAA AAC AGA AGT GAA A-3', MMP-3 (forward) 5'GAC ACC AGC ATG AAC CTT GTT-3' (reverse) 5'-GGA ACC GAG TCA GGA CTATG-3', COX -2 (forward) 5'-TCC TTG CTG TTC CCA CCC ATG-3' (reverse) 5'-CAT CAT CAG ACC AGG CAC CAG-3', GAPDH (forward) 5'-AAA TCA AGT GGG GCG ATG CT-3' (reverse) 5'-AGC TTC CCG TTC AGC TCA GG-3'. The products were subjected to electrophoresis in $1 \%$ agarose gel. The bands were visualized by staining with ethidium bromide. Densitometric analysis was performed on the relative intensity of each band (MultiGauge program, version 3.0, Fuji film, Tokyo, Japan).

Western blotting: RASFs were cultured with/without IL$1 \beta(1.0 \mathrm{ng} / \mathrm{mL})$ and/or tangeretin $(50$ or $100 \mu \mathrm{M})$. RASFs $\left(1 \times 10^{6}\right.$ cells $)$ were seeded on $100-\mathrm{mm}$ culture dishes and harvested in PBS. After washing with PBS, cell pellets were lysed with lysis buffer (20 mM HEPES, $\mathrm{pH} 7.2,150 \mathrm{mM} \mathrm{NaCl}, 1 \%$ Triton X-100, $0.1 \mathrm{mM}$ phenylmethylsulfonyl fluoride, $1 \mu \mathrm{g} / \mathrm{mL}$ aprotinin, $1 \mathrm{mM}$ EDTA). After incubation for $30 \mathrm{~min}$ at $4^{\circ} \mathrm{C}$, cellular debris were removed by centrifugation at 100,000 $\mathrm{g}$ for $30 \mathrm{~min}$, and supernatants were analyzed by SDS-PAGE. For COX-2 immunoblotting the cell membranes were prepared from isolated RASFs as described previously (Hodgkin et al., 1990). To determine the cytoplasmic $\mathrm{IkB}$, cytoplasmic extracts were prepared (Lee et al., 2006). To analyze NF-kB (p65), nuclear extract was prepared using a previously described method (Lee et al., 2006). Protein concentration was determined by BioRad protein assay kit (Bio-Rad Laboratories, USA). Proteins were then fractionated by SDS-PAGE, electro transferred to nitrocellulose membranes, blotted with respective antibodies (MMP-1, MMP-3, TIMP, COX-2, ERK, p-ERK- 1/2, p-38, p-p38 MAPK, JNK, p-JNK, NF$\mathrm{kB}$ (p65), IkBa, and $\beta$-actin) and the immunoreactive bands were detected by enhanced chemiluminescence (GE Healthcare).

Assay of PGE2 production: To analyse PGE2 production in RASFs, the cells $\left(1 \times 10^{4}\right.$ cells $)$ were grown in $25 \mathrm{~cm}^{2}$ tissue culture flasks for 48 hours before treatment and starved serum overnight before stimulation with IL-1 $\beta$. After washing with PBS ( $\mathrm{pH} 7.4)$, RASFs were pretreated with IL-1 $\beta(1.0 \mathrm{ng} / \mathrm{mL})$ and/ or tangeretin (50 or $100 \mu \mathrm{M}$ ) for 48 hours at $37^{\circ} \mathrm{C}$ in DMEM supplemented with $10 \%(\mathrm{v} / \mathrm{v})$ FCS in an atmosphere of $5 \%$ $\mathrm{CO}_{2}$ (Sung et al., 2012). The supernatant was collected after incubation for 48 hours. The levels of PGE2 in the medium were determined by ELISA kit (R\&D Systems, Minneapolis, MN, USA).

Statistical analysis: All data were expressed as the mean $\pm \mathrm{SD}$ of results of three or six individual experiments. The data were analyzed using SPSS (free version).
Group mean values were compared by one-way ANOVA. The values at $\mathrm{p}<0.05$ were considered significant.

\begin{abstract}
Results
Tangeretin inhibits $I L-1 \beta$ induced proliferation and induces apoptosis of RASFs: IL-1 $\beta$ is a well-known potent growth-promoting factor of synovial fibroblasts. IL-1 $\beta$ induced the proliferation of RASFs significantly $(p<0.05)$ as compared with the control cells cultured in DMSO without tangeretin (Figure 1a). Exposure to tangeretin $(50$ or $100 \mu \mathrm{M})$ significantly $(\mathrm{p}<0.05)$ inhibited the proliferation of RASFs treated with or without IL-1 $\beta$ ( $p<0.05)$. The decrease in cell proliferation and viability was almost multifold as compared to IL-1 $\beta$ induction alone. Further, the effects of tangeretin on apoptotic counts of RASFs were examined by flow cytometry. IL-1 $\beta$ induced increased proliferation is accompanied with a marked decrease in apoptotic cell counts. However, the percentage of annexin V-positive cells was observed to be significantly increased in the RASFs treated with tangeretin at both the doses as compared with the cells cultured without tangeretin $(p<0.05)$ (Figure 1b;1c). Tangeretin at $100 \mu \mathrm{M}$ dose was observed to be more effective in reducing cell viability and inducing apoptosis than at $50 \mu \mathrm{M}$.
\end{abstract}

Effects of tangeretin on IL-1 $\beta$ induced MMP-1, MMP-3 and TIMP-1 mRNA expression: Studies have reported the expression of COX- 2 and MMPs in human RASFs is enhanced by pro-inflammatory cytokines such as IL-1 $\beta$ (Crofford et al., 1994; Tolboom et al., 2002). In our study to evaluate the effects of tangeretin on expression of MMP-1, MMP-3 and TIMP-1 genes under the influence of IL-1 $\beta$, RT-PCR was performed. RASFs were stimulated with IL-1 $\beta$ (1.0 ng/mL). IL-1 $\beta$ significantly $(\mathrm{p}<0.05)$, enhanced the mRNA levels of MMP-1 and MMP-3 in RASFs nearly twice. However much changes were not observed in TIMP-1 mRNA levels. Co-treatment with tangeretin with IL-1 $\beta$ caused a marked $(\mathrm{p}<0.05)$ decline in the mRNA levels of MMP-1 and MMP-3 (Figure 2). The inhibition of mRNA expression was more obvious on exposure to $100 \mu \mathrm{M}$. Further, inhibition of the expression of MMPs was in a dosedependent manner in both unstimulated and IL-1 $\beta$ stimulated RASFs, indicating the anti-inflammatory potential of tangeretin.

Attenuation of IL-1 $\beta$-induced COX-2 expression by tangeretin: COX-2 is a major enzyme that catalyzes the synthesis of various PGs including PGE2 (Smith et al., 1996). We determined the effect of tangeretin on IL-1 $\beta$ induced COX-2 expression in synovial fibroblasts. RASFs were co-treated with $1.0 \mathrm{ng} / \mathrm{mL}$ IL-1 $\beta$ and/or tangeretin $(50$ or $100 \mu \mathrm{M})$ for 12,24 or 48 hours, and COX-2 mRNA levels were detected by RT-PCR. Tangeretin significantly attenuated the IL- $1 \beta$-induced 


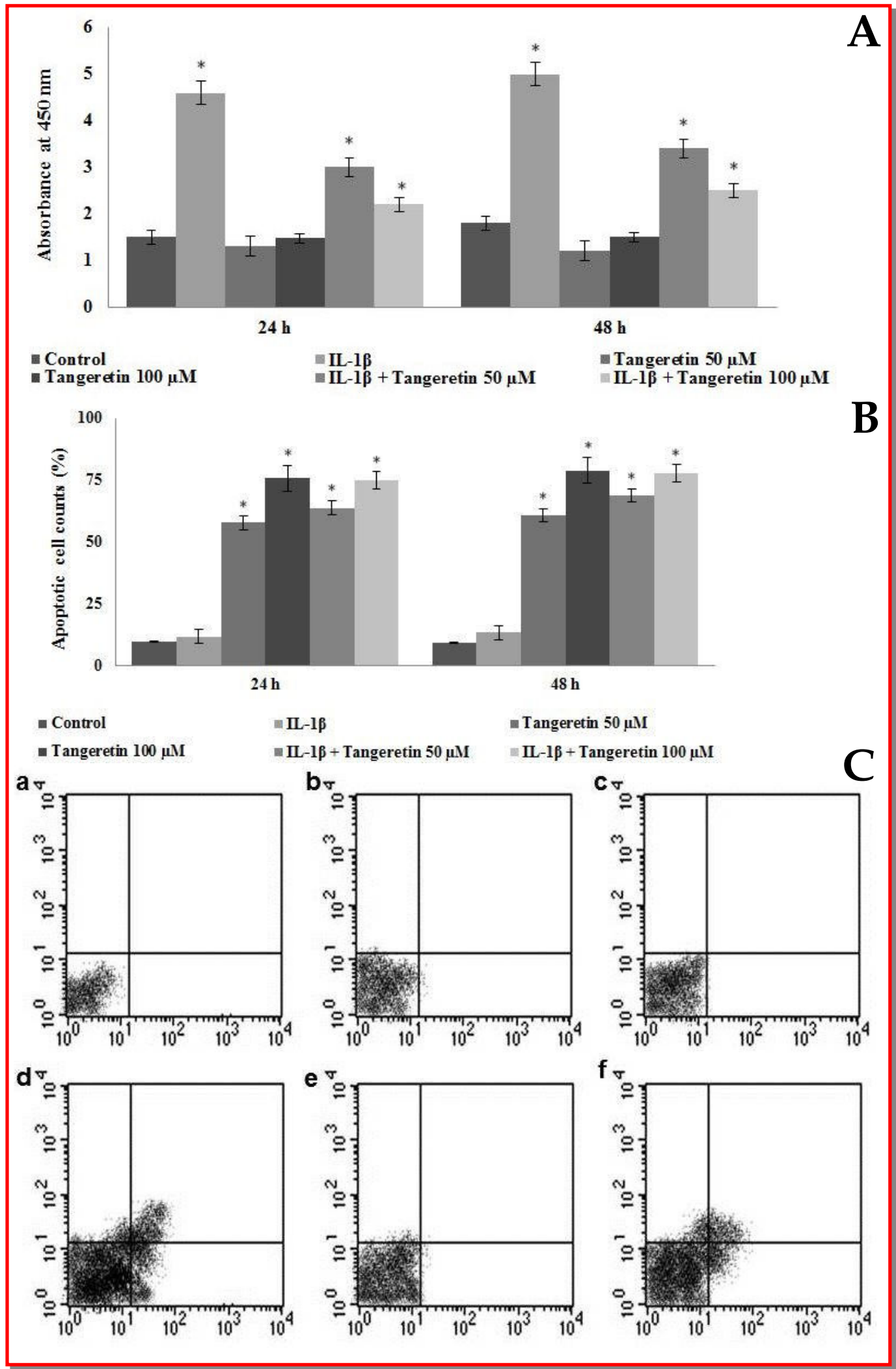

Figure 1: Influence of tangeretin on IL-1 $\beta$ induced proliferation of RASFs

Exposure to tangeretin $(50$ or $100 \mu \mathrm{M})$ significantly $(\mathrm{p}<0.05)$ inhibited the proliferation of RASFs in a dose-dependent manner $(\mathrm{A})$ and as well significantly induced apoptosis as seen by increased apoptotic cell counts by annexin V staining (B and C); [a-Control; b-IL-1 $\beta$; c-tangeretin $50 \mu \mathrm{M}$; dtangeretin $100 \mu \mathrm{M}$; e-IL-1 $\beta$ + tangeretin $50 \mu \mathrm{M}$; f-IL- $1 \beta$ + tangeretin $100 \mu \mathrm{M}$; Values are represented as mean \pm SD; $\mathrm{n}=6$; *represents statistical significance at $\mathrm{p}<0.05$ compared against control as determined by one-way ANOVA 


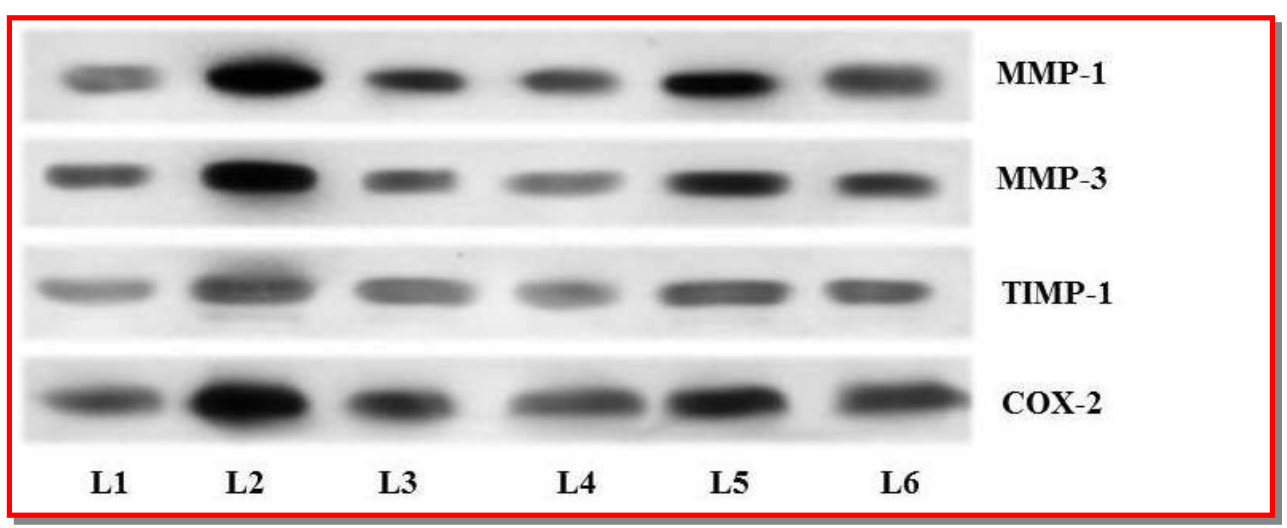

Figure 2: Influence of tangeretin on IL-1 $\beta$ induced MMP-1, MMP-3 and TIMP-1 mRNA expression

L1-Control; L2-IL-1 $\beta$; L3-Tangeretin $50 \mu \mathrm{M}$; L4-Tangeretin $100 \mu \mathrm{M}$; L5-IL-1 $\beta$ + Tangeretin $50 \mu \mathrm{M}$; L6-IL-1 + Tangeretin $100 \mu \mathrm{M}$

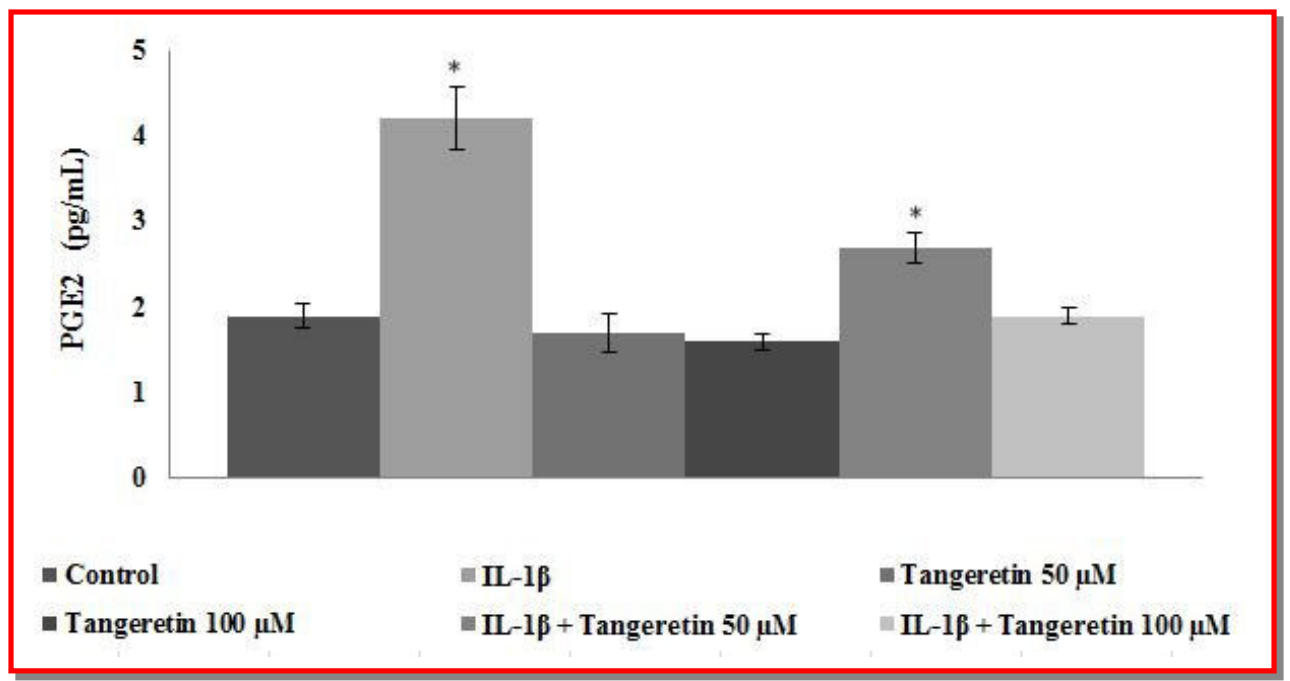

Figure 3: Tangeretin inhibits IL-1 $\beta$-induced PGE2 production in RASFs

Values are represented as mean $\pm \mathrm{SD} ; \mathrm{n}=6$; *represents statistical significance at $\mathrm{p}<0.05$ compared against control as determined by one-way ANOVA

COX-2 mRNA expression on 12, 24 or 48 hours. Exposure to tangeretin at $100 \mu \mathrm{M}$ caused a more significant inhibition of COX-2 mRNA expression. The cells revealed a dose-dependent inhibitory effect of tangeretin on the IL- $1 \beta$-induced increase in COX-2 mRNA levels (Figure 2). In addition, immunoblotting showed that tangeretin could attenuate the IL-1 $\beta$ induced COX-2 protein increase $(\mathrm{p}<0.05)$.

Tangeretin inhibits $I L-1 \beta$-induced PGE2 production in RASFs: PGE2 is a pleiotropic mediator of inflammation and its excessive production is associated with many pathologic processes. PGE2 plays a vital role in eliciting signs and symptoms of inflammation (Martel-Pelletier et al., 2004). We investigated the effects of tangeretin on PGE2 production by RASFs. RASFs were cultured with IL-1 $\beta(1.0 \mathrm{ng} / \mathrm{mL})$ for 48 hours. A multifold increases in PGE2 production occurred after IL-1 $\beta$ treatment $(\mathrm{p}<0.05)$ in comparison to cells not exposed to IL-1 $\beta$. However, tangeretin treatment markedly inhibited PGE2 production in a dose-dependent manner. The levels of PGE2 were in line with the results of COX-2 expression, indicating that suppression of COX-2 decreased PGE2 production (Figure 3).

Effect of tangeretin on IL-1 $\beta$-induced signal pathways in RASFs: The influence of tangeretin on the expression of MAPK pathway proteins and NF - $\mathrm{\kappa B}$ were determined by Western blotting. MAPK pathway is involved in regulation of cell proliferation, apoptosis, cytokine expression and MMP production (Kim et al., 2006). $\mathrm{NF}-\mathrm{kB}$ and MAPKs have been reported to participate in the pathogenic mechanisms of inflammation and the destruction of joints in RA. IL-1 $\beta$ at $1.0 \mathrm{ng} / \mathrm{mL}$ caused activation of the intracellular MAPKs including ERK, p38 , and JNK resulting in marked increase in the phosphorylation status of these proteins as well increase in MMP levels (Figure 4 a-h).

However, tangeretin significantly down-regulated IL$1 \beta$-induced phosphorylation of JNK, ERK, and p38. The inhibition of phosphorylation by tangeretin was observed to be time and dose-dependent. Furthermore, tangeretin reduced the expressions of MMPs and COX- 


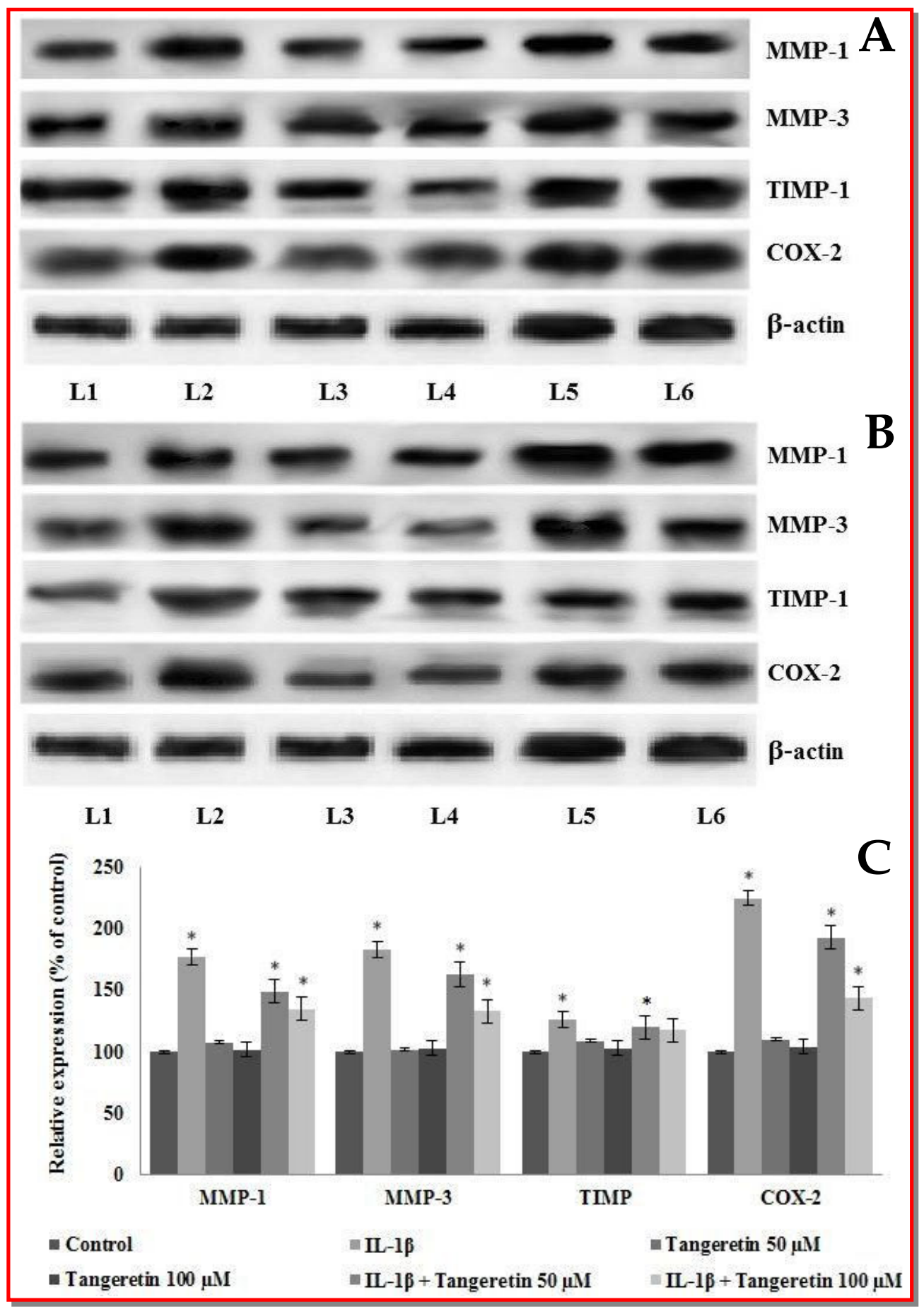

Figure 4: Influence of tangeretin on IL-1 $\beta$-induced protein expressions

Tangeretin significantly reduced the IL-1 $\beta$-induced raised expressions of MMPs and COX-2 following 24 hours (A and C) and 48 hours (B and D) of exposure. IL-1 $\beta$-induced marked increases in the phosphorylation status and as well increased expressions of MAPK pathway proteins were regulated by tangeretin at both the doses $(50$ and $100 \mu \mathrm{M})$ and at 24 hours (E and G) and 48 hours (F and H); L1-control; L2-IL-1 $\beta$; L3-tangeretin 50 $\mu$ M; L4tangeretin $100 \mu \mathrm{M}$; L5-IL-1 $\beta$ + tangeretin $50 \mu \mathrm{M}$; L6-IL-1 $\beta$ + tangeretin $100 \mu \mathrm{M}$; Values are represented as mean \pm SD; n=3; *represents statistical significance at $\mathrm{p}<0.05$ compared against control as determined by one-way ANOVA

2. Nuclear translocation and activation of NF-kB is known to be dependent on phosphorylation and subsequent degradation of IkBa (Adcock, 1997). While IL-1 $\beta$ caused marked activation of NF-kB and p65, significant decrease of cytoplasmic IkBa was observed in RASFs. NF-kB activation was observably inhibited by tangeretin with considerable increase in cytoplasmic IkBa (Figure $5 \mathrm{a}-\mathrm{d}$ ). These results indicate that tange- 


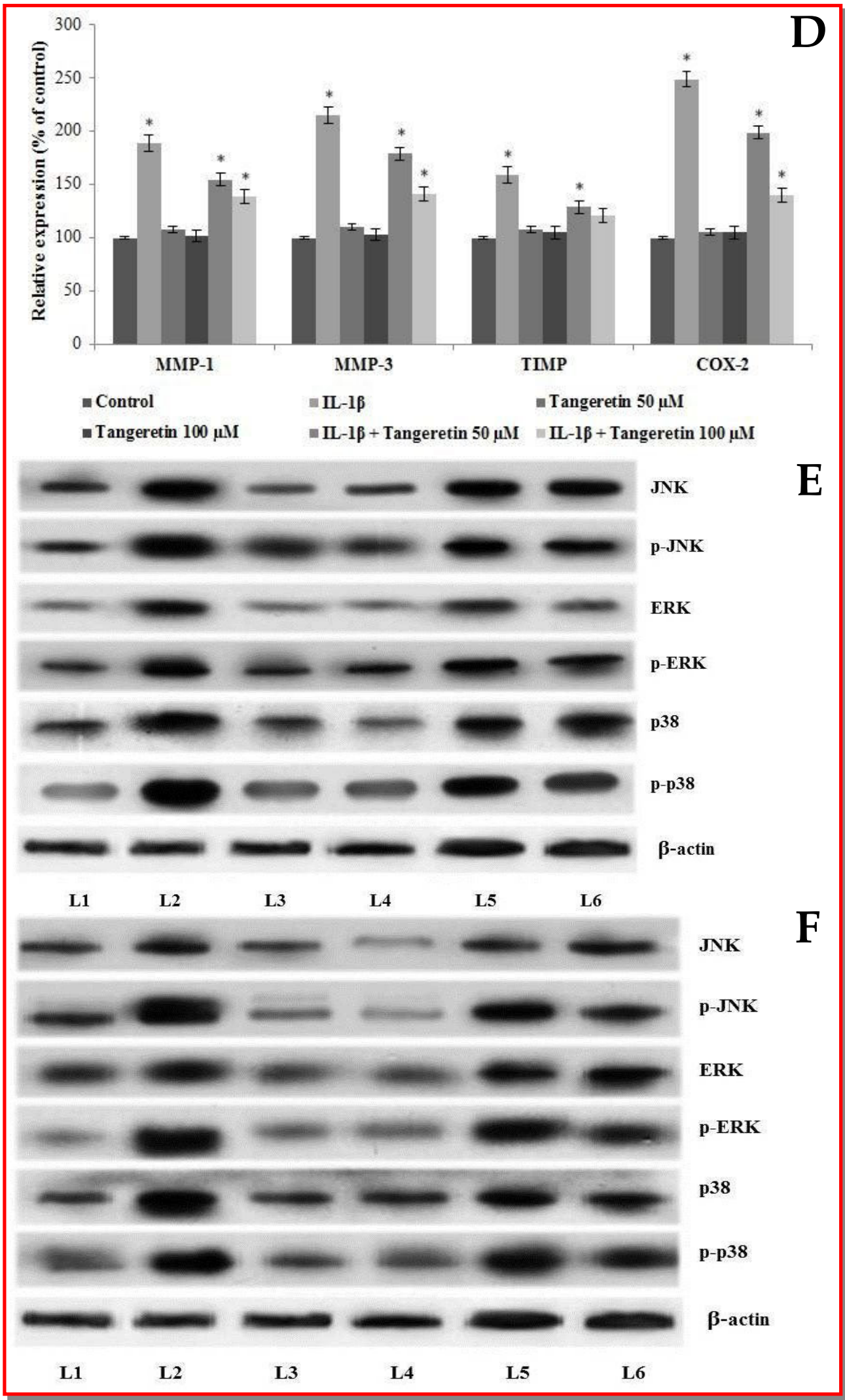

Figure 4: Influence of tangeretin on IL-1 $\beta$-induced protein expressions (Cont.)

Tangeretin significantly reduced the IL-1 $\beta$-induced raised expressions of MMPs and COX-2 following 24 hours (A and C) and 48 hours (B and D) of exposure. IL-1 $\beta$-induced marked increases in the phosphorylation status and as well increased expressions of MAPK pathway proteins were regulated by tangeretin at both the doses ( 50 and $100 \mu \mathrm{M})$ and at 24 hours (E and G) and 48 hours (F and H); L1-Control; L2-IL-1 $\beta$; L3-Tangeretin $50 \mu \mathrm{M}$; L4Tangeretin $100 \mu \mathrm{M}$; L5-IL-1 $\beta$ + Tangeretin $50 \mu \mathrm{M}$; L6-IL-1 + Tangeretin $100 \mu \mathrm{M}$; Values are represented as mean \pm SD; n=3; *represents statistical significance at $\mathrm{p}<0.05$ compared against control as determined by one-way ANOVA 


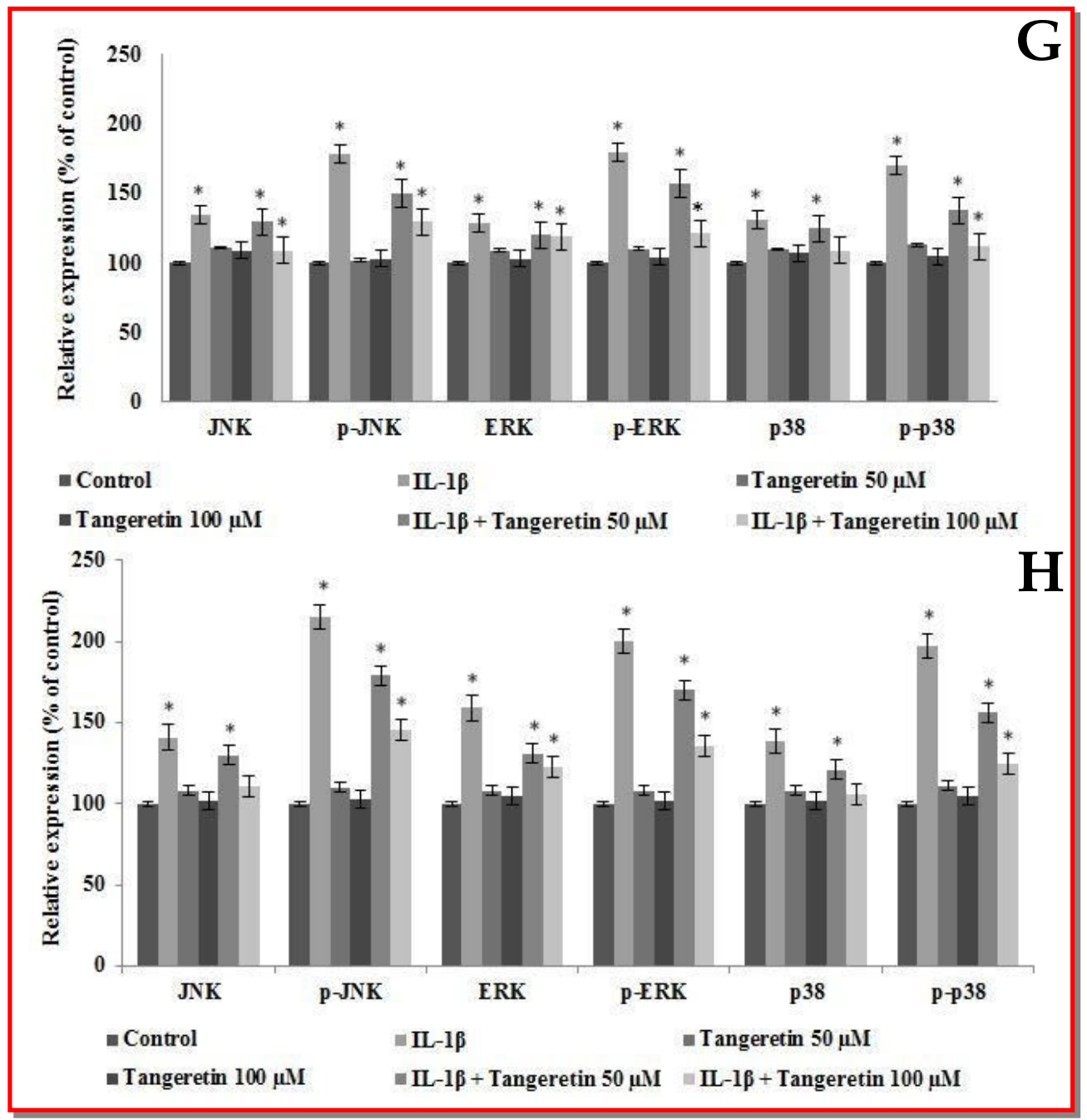

Figure 4: Influence of tangeretin on IL-1 $\beta$-induced protein expressions (Cont.)

Tangeretin significantly reduced the IL-1 $\beta$-induced raised expressions of MMPs and COX-2 following 24 hours (A and C) and 48 hours (B and D) of exposure. IL-1 $\beta$-induced marked increases in the phosphorylation status and as well increased expressions of MAPK pathway proteins were regulated by tangeretin at both the doses $(50$ and $100 \mu \mathrm{M})$ and at 24 hours (E and G) and 48 hours (F and H); L1-Control; L2-IL-1 $\beta$; L3-tangeretin 50 $\mu \mathrm{M}$; L4tangeretin $100 \mu \mathrm{M}$; L5-IL-1 $\beta$ + tangeretin $50 \mu \mathrm{M}$; L6-IL-1 $\beta$ + tangeretin $100 \mu \mathrm{M}$; Values are represented as mean \pm SD; n=3; *represents statistical significance at $\mathrm{p}<0.05$ compared against control as determined by one-way ANOVA

retin potentially inhibited IL- $1 \beta$-induced, expression of COX-2 and regulated the intracellular MAPKs and NFKB pathways.

\section{Discussion}

Pathogenesis of RA involves cellular infiltration into the synovium and increase of inflammatory cytokines such as TNF- $\alpha$, IL-1 $\beta$, and IL-6 consequently leading to cartilage and bone erosion (Arend, 2001; Choy and Panayi, 2001; Pratt et al., 2009; Choy, 2012). RASFs play critical role in the pathogenesis of RA by involvement in angiogenesis and in regulation of the inflammatory cells (Cawston, 1995; Han et al., 2003). Strategies that aim in blocking either the proliferation of RASFs or production of the inflammatory mediators are possible means of therapy against RA.
In our study, tangeretin potentially reduced the proliferation of RASFs and also raised the apoptotic cell counts. The aggressive proliferation of RASFs is the main mechanism for the hyperplasic growth of the RA synovium. Cytokine -IL-1 $\beta$ induces the proliferation of RASFs and plays an vital role in the pathogenesis of inflammatory synovitis and joint destruction (Gitter et al., 1989; Williams et al. 2007; Tanida et al., 2009; Choy, 2012). The results indicate that tangeretin (50 and 100 $\mu \mathrm{M})$ significantly inhibits IL- $1 \beta$-induced proliferation of RASFs in a dose- and time-dependent manner. Further tangeretin was also able to reduce proliferation of synovial fibroblasts not exposed to IL-1 $\beta$ as well.

Studies have shown that pro-inflammatory cytokines including IL- $1 \beta$ could enhance the expression of COX-2 and MMPs in human RASFs (Tolboom et al., 2002). MMPs play a key role in the destruction of the 


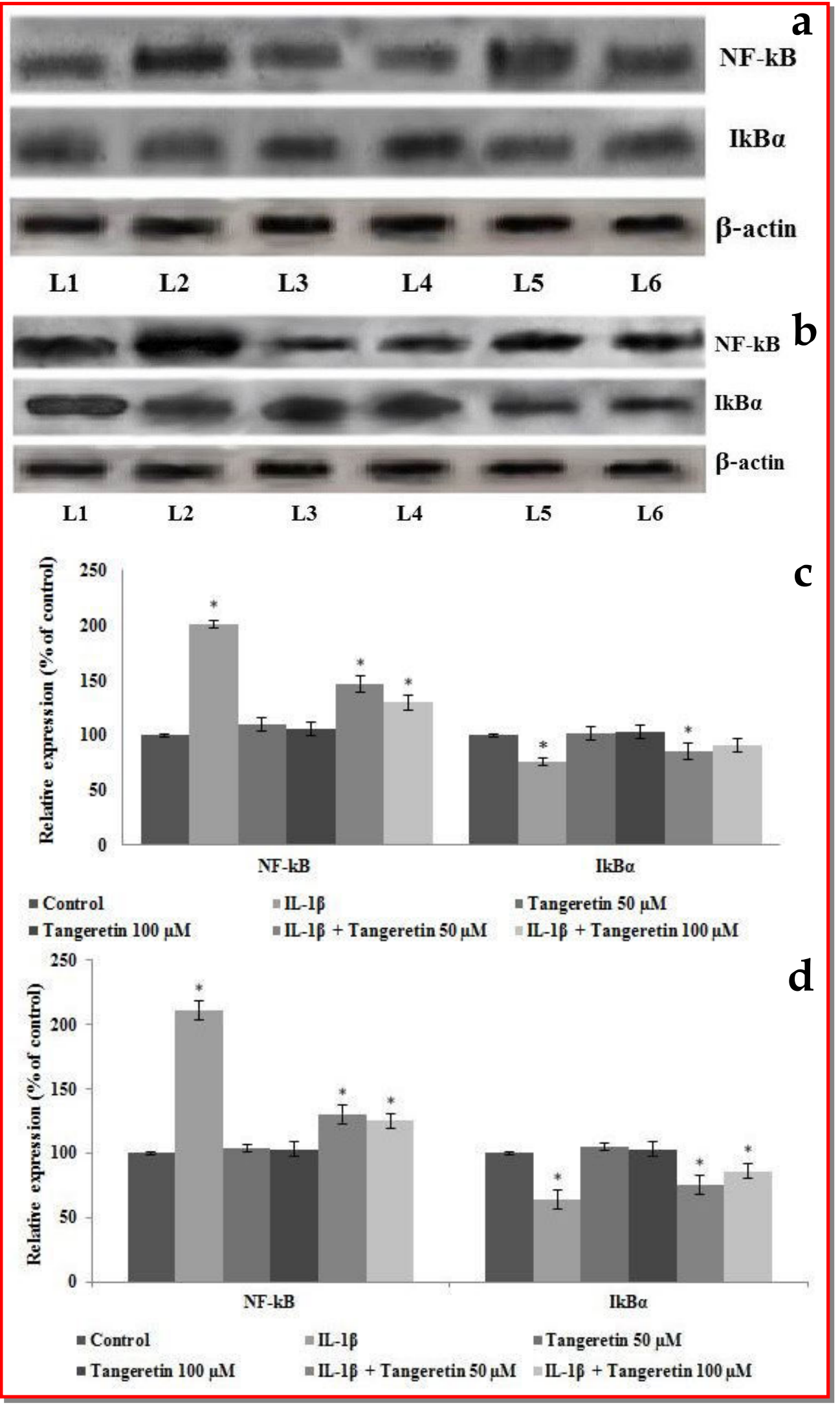

Figure 5: Tangeretin regulates the expressions of NF-kB and IkBa

Tangeretin significantly reduced the NF-kB expression and regulated IkBa; Following 24 hours (a and c) and $48 \mathrm{~h}$ (b and d) of exposure; L1-control; L2-IL-1 $\beta$; L3-tangeretin $50 \mu \mathrm{M}$; L4-tangeretin $100 \mu \mathrm{M}$; L5-IL-1 $\beta+$ tangeretin $50 \mu \mathrm{M}$; L6-IL-1 $\beta+$ tangeretin $100 \mu \mathrm{M}$; Values are represented as mean \pm $\mathrm{SD} ; \mathrm{n}=3$; *represents statistical significance at $\mathrm{p}<0.05$ compared against control as determined by one-way ANOVA 
extracellular matrix in articular structures. The cartilage destruction in RA is mainly caused by the activation of MMPs (Feldmann et al., 1996). MMP-1 and -3 have been shown to be the major enzymes produced by the synovial fibroblasts (Konttinen et al., 1999). MMP-1 preferentially degrades fibrillar collagens, whereas MMP-3 degrades a broad array of extracellular matrix substrates (Ogata et al., 1992; Knauper et al., 1996; Jackson et al., 2001). COX-2 is involved in the synthesis of inflammatory mediators and is responsible for the conversion of the free arachidonic acid to prostaglandins and variety of bioactive products. PGE2, a pleiotropic mediator of inflammation, is involved in various pathological processes and further when in excess, it also elicits the signs and symptoms of inflammation (Martel-Pelletier et al., 2004). In this study we observed that tangeretin at both the doses were able to down-regulate the IL-1 $\beta$-induced expressions of MMP-1,3 and COX-2 both at the mRNA and protein levels. Down-regulation of COX-2 observed in tangeretin treatment also reflected in the levels of PGE2. We found that tangeretin caused marked decreases in the levels of PGE2 in a dose-dependent manner.

The pro-inflammatory cytokines, upon binding to the respective receptors initiate various signalling pathways. Cytokines, IL-1 induce the activation of NF-kB in RA (Morel and Berenbaum, 2004; Rannou et al., 2006; Lie et al., 2012). NF-kB is an important transcriptional factor complex that regulates the expression of various genes involved in the process of inflammatory response (Karin and Lin, 2002; Shaulian and Karin, 2002). In the cell under normal conditions, NF-kB is maintained in an inactive state within the cytoplasm sequestered by IkB. Upon stimulation chemokines like IL-1, the IkB kinase complex gets activated leading to phosphorylation and degradation of IkBa. This further causes a transitory increase in unbound NF-kB molecules that get activated and translocate to the nucleus, resulting in transcription of inflammatory responsive genes (Tak and Firestein, 2001; Aggarwal, 2004). Thus, the increase in NF-kB observed following IL-1 $\beta$ treatment in our study is correlating with the concurrent decrease in expression of IkBa. Tangeretin was able to considerably regulate the expressions of IkBa and NF-kB. At both the doses (50 and $100 \mu \mathrm{M})$ tangeretin significantly down-regulated NF-kB. The results suggest that tangeretin was able to inhibit IL-1 $\beta$ induced inflammatory responses as evident from marked decrease in the cell proliferation and production of PGE2.

MAPKs are involved in a wide variety of cellular processes such as inflammation (Su and Karin, 1996; Dong et al., 2002). The major members of MAPK families - ERK, JNK, and p38 kinases, are expressed in active forms in synovial tissue and in cultured RASFs (Schett et al., 2000; Han et al., 2001; Sweeney and Firestein, 2004). Several reports have demonstrated that inhibitors of $\mathrm{NF}^{-} \mathrm{KB}$ or MAPKs reduce synovial inflammation, bone destruction and cartilage damage in animal models of arthritis (McIntyre et al., 2003; Nishikawa et al., 2003). In our study, increased activated forms of MAPK kinases (JNK, ERK, p38) were seen upon IL-1 $\beta$ exposure suggesting the activation of the signal transduction pathways. However, significant down-regulation in the phosphorylated forms of ERK, JNK and p38 kinases were observed following tangeretin exposure, suggesting that tangeretin was able to effectively regulate the alterations in the MAPK signalling cascades in RASFs.

\section{Conclusion}

Tangeretin was found effective in inhibiting IL- $1 \beta$ induced RASFs proliferation and also regulates the inflammatory responses. It also reduced the signalling pathways, blocked the expressions of transcription factors, reduced the generation and effects of chemokines.

\begin{tabular}{l}
\hline References \\
Adcock IM. Transcription Factors as Activators of Gene \\
Transcription: AP-1 and NF-kappa B. In: Monaldi Archives \\
for chest disease (Archivio Monaldi per le malattie del \\
torace/Fondazione clinica del lavoro). Vol. 52. IRCCS [and] \\
Istituto di clinica tisiologica e malattie apparato respiratorio, \\
Universita di Napoli, Secondo Ateneo. 1997, pp 178-86.
\end{tabular}

Aggarwal BB. Nuclear factor-kappa B: The enemy within. Cancer Cell. 2004; 6: 203-08.

Arend WP. Cytokines and cellular interactions in inflammatory synovitis. J Clin Invest. 2001; 107: 1081-82.

Arnett FC, Edworthy SM, Bloch DA, Mcshane DJ, Fries JF, Cooper NS, Healey LA, Kaplan SR, Liang MH, Luthra HS. The American Rheumatism Association 1987 revised criteria for the classification of rheumatoid arthritis. Arthritis Rheum. 1998; 31: 315-24.

Cawston TE. Proteinase and connective tissue breakdown. In: Mechanisms and models in rheumatoid arthritis. Henderson B, Edwards JCW, Pettipher ER (eds). London, Academic Press, 1995.

Chen ZT, Chu HL, Chyau CC, Chu CC, Duh PD. Protective effects of sweet orange (Citrus sinensis) peel and their bioactive compounds on oxidative stress. Food Chem. 2012; 135: 2119-27.

Choy EH, Panayi GS. Cytokine pathways and joint inflammation in rheumatoid arthritis. N Engl J Med. 2001; 344: 907-16.

Choy E. Understanding the dynamics: Pathways involved in the pathogenesis of rheumatoid arthritis. Rheumatology 2012; 51: v3-11.

Crofford LJ, Wilder RL, Ristimaki AP, Sano H, Remmers EF, Epps HR, Hla T. Cyclooxygenase- 1 and -2 expression in rheumatoid synovial tissues: Effects of interleukin- 1 beta, phorbol ester, and corticosteroids. J Clin Invest. 1994; 93: 1095-101. 
Datla KP, Christidou M, Widmer WW, Rooprai HK, Dexter DT. Tissue distribution and neuroprotective effects of citrus flavonoid tangeretin in a rat model of Parkinson's disease. Neuroreport. 2001; 12: 3871-75.

Dong C, Davis RJ, Flavell RA. MAPkinases in the immune response. Annu Rev Immunol. 2002; 20: 55-72.

Dong Y, Cao A, Shi J, Yin P, Wang L, Ji G, Xie J, Wu D. Tangeretin, a citrus polymethoxyflavonoid, induces apoptosis of human gastric cancer AGS cells through extrinsic and intrinsic signaling pathways. Oncol Rep. 2014; 31: 178894.

Feldmann M, Brennan FM, Maini RN. Role of cytokines in rheumatoid arthritis. Annu Rev Immunol. 1996; 14: 397-440.

Gitter BD, Labus JM, Lees SL, Scheetz ME. Characteristics of human synovial fibroblast activation by IL-1 beta and TNF alpha. Immunology 1989; 66: 196-200.

Han Z, Boyle DL, Chang L, Bennett B, Karin M, Yang L, Manning AM, Firestein GS. c-Jun N-terminal kinase is required for metalloproteinase expression and joint destruction in inflammatory arthritis. J Clin Invest. 2001; 108: 73-81.

Han MK, Kim JS, Park BH, Kim JR, Hwang BY, Lee HY, Song EK, Yoo WH. NF-kappaB dependent lymphocyte hyperadhesiveness to synovial fibroblasts by hypoxia and reoxygenation: Potential role in rheumatoid arthritis. J Leukocyte Biol. 2003; 73: 525-29.

Ho SC, Kuo CT. Hesperidin, nobiletin, and tangeretin are collectively responsible for the anti-neuroinflammatory capacity of tangerine peel (Citri reticulatae pericarpium). Food Chem Toxicol. 2014; 71: 176-82.

Hodgkin PD, Yamashita LC, Coffman RL, Kehry MR. Separation of events mediating $\mathrm{B}$ cell proliferation and Ig production by using $\mathrm{T}$ cell membranes and lymphokines. J Immunol. 1990; 145: 2025-34.

Jackson C, Nguyen M, Arkell J, Sambrook P. Selective matrix metalloproteinase (MMP) inhibition in rheumatoid arthritistargetting gelatinase A activation. Inflamm Res. 2001; 50: 183 $-86$.

Karin M, Lin A. NF-kappaB at the cross roads of life and death. Nat Immunol. 2002; 3: 221-27.

Kim HG, Shrestha B, Lim SY, Yoon DH, Chang WC, Shin DJ, Han SK, Park SM, Park JH, Park HI, Sung JM, Jang Y, Chung N, Hwang KC, Kim TW. Cordycepin inhibits lipopolysaccharide-induced inflammation by the supperssion of NF-kB through Akt and p38 inhibition in Raw 264.7 macrophage cells. Eur J Pharmacol. 2006; 545: 192-99.

Knauper V, Lopez-Otin C, Smith B, Knight G, Murphy G. Biochemical characterization of human collagenase-3. J Biol Chem. 1996; 271: 1544-50.

Konttinen YT, Ainola M, Valleala H, Ma J, Ida H, Mandelin J, Kinne RW, Santavirta S, Sorsa T, López-Otín C, Takagi M. Analysis of 16 different matrix metalloproteinases (MMP-1 to MMP-20) in the synovial membrane: Different profiles in trauma and rheumatoid arthritis. Ann Rheum Dis. 1999; 58: 691-97.

Lee HY, Jeon HS, Song EK, Han MK, Park SI, Lee SI, Yun HJ, Kim JR, Kim JS, Lee YC, Kim SI, Kim HR, Choi JY, Kang I,
Kim HY, Yoo WH. CD40 ligation of rheumatoid synovial fibroblasts regulates RANKL-mediated osteoclastogenesis: Evidence of NF-kappaB-dependent, CD40-mediated bone destruction in rheumatoid arthritis. Arthritis Rheum. 2006; 54: $1747-58$.

Lie PP, Cheng CY, Mruk DD. The biology of interleukin-1: Emerging concepts in the regulation of the actin cytoskeleton and cell junction dynamics. Cell Mol Life Sci. 2012; 69: 487-500.

Luo SF, Fang RY, Hsieh HL, Chi PL, Lin CC, Hsiao LD, Wu CC, Wang JS, Yang CM. Involvement of MAPKs and NFkappaB in tumor necrosis factor alpha-induced vascular cell adhesion molecule1expression in human rheumatoid arthritis synovial fibroblasts. Arthritis Rheum. 2010; 62: 10516.

Martel-Pelletier J, Pelletier JP, Fahmi H. New insights into prostaglandin biology. J Rheumatol. 2004; 31: 14-16.

McIntyre KW, Shuster DJ, Gillooly KM, Dambach DM, Pattoli MA, Lu P, Zhou XD, Qiu Y, Zusi FC, Burke JR. A highly selective inhibitor of I kappa B kinase, BMS-345541, blocks both joint inflammation and destruction in collagen-induced arthritis in mice. Arthritis Rheum. 2003; 48: 2652-59.

Morel J, Berenbaum F. Signal transduction pathways: New targets for treating rheumatoid arthritis. Joint Bone Spine. 2004; 71: 503-10.

Nishikawa M, Myoui A, Tomita T, Takahi K, Nampei A and Yoshikawa H. Prevention of the onset and progression of collagen-induced arthritis in rats by the potent p38 mitogen-acti-vated protein kinase inhibitor FR167653. Arthritis Rheum. 2003; 48: 2670-81.

Ogata Y, Enghild JJ, Nagase H. Matrix metalloproteinase 3 (stromelysin) activates the precursor for the human matrix metalloproteinase 9. J Biol Chem. 1992; 267: 3581-84.

Periyasamy K, Baskaran K, Ilakkia A, Vanitha K, Selvaraj S, Sakthisekaran D. Antitumor efficacy of tangeretin by targeting the oxidative stress mediated on 7,12dimethylbenz(a) anthracene-induced proliferative breast cancer in Sprague-Dawley rats. Cancer Chemother Pharmacol. 2015; 75: 263-72.

Pope RM. Apoptosis as a therapeutic tool in rheumatoid arthritis. Nat Rev Immunol. 2002; 2: 527-35.

Pratt AG, Isaacs JD, Mattey DL. Current concepts in the pathogenesis of early rheumatoid arthritis. Best Pract Res Clin Rheumatol. 2009; 23: 37-48.

Rannou F, Francois M, Corvol MT, Berenbaum F. Cartilage breakdown in rheumatoid arthritis. Joint Bone Spine. 2006; 73: 29-36.

Schett G, Tohidast-Akrad M, Smolen JS , Schmid BJ, Steiner CW, Bitzan P, Zenz P, Redlich K, Xu Q, Steiner G. Activation, differential localization, and regulation of the stressactivated protein kinases, extracellular signal-regulated kinase, c-jun N-terminal kinase, and p38 mitogen-activated protein kinase, in synovial tissue and cells in rheumatoid arthritis. Arthritis Rheum. 2000; 43: 2501-12.

Shaulian E, Karin M. AP-1 as a regulator of cell life and death. Nat Cell Biol. 2002; 4: E131-36. 
Shu Z, Yang B, Zhao H, Xu B, Jiao W, Wang Q, Wang Z, Kuang $H$. Tangeretin exerts anti-neuroinflammatory effects via NF$\mathrm{\kappa B}$ modulation in lipopolysaccharide-stimulated microglial cells. Int Immunopharmacol. 2014; 19: 275-82.

Smith WL, Garavito RM, DeWitt DL. Prostaglandin endoperoxide $\mathrm{H}$ synthases (cyclooxygenases)-1 and -2. J Biol Chem. 1996; 271: 33157-60.

Su B, Karin M. Mitogen-activated protein kinase cascades and regulation of gene expression. Curr Opin Immunol. 1996; 8: 402-11.

Sung MS, Lee EG, Jeon HS, Chae HJ, Park SJ, Lee YC, Yoo WH. Quercetin inhibits IL-1 $\beta$ induced proliferation and production of MMPs, COX-2 and PGE2 by rheumatoid synovial fibroblast. Inflammation 2012; 35: 1585-94.

Sweeney SE, Firestein GS. Signal transduction in rheumatoid arthritis. Curr Opin Rheumatol. 2004; 16: 231-37.

Tak PP, Firestein GS. NF-kappaB: A key role in inflammatory diseases. J Clin Invest. 2001; 107: 7-11.

Tanida S, Yoshitomi H, Nishitani K, Ishikawa M, Kitaori T, Ito $\mathrm{H}$, Nakamura T. CCL20 produced in the cytokine network of rheumatoid arthritis recruits CCR6+ mononuclear cells and enhances the production of IL-6. Cytokine 2009; 47: 11218.

Tas SW, Remans PH, Reedquist KA, Tak PP. Signal transduction pathways and transcription factors as therapeutic targets in inflammatory disease: Towards innovative antirheumatic therapy. Curr Pharma Design 2005; 11: 581-611.

Tolboom TC, Pieterman E, van der Laan WH, Toes RE, Huidekoper AL, Nelissen RG, Breedveld FC, Huizinga TW. Invasive properties of fibroblast-like synoviocytes: Correlation with growth characteristics and expression of MMP-1, MMP-3, and MMP-10. Annals Rheum Dis. 2002; 61: 975-80.

Williams RO, Paleolog E, Feldmann M. Cytokine inhibitors in rheumatoid arthritis and other autoimmune diseases. Curr Opin Pharmacol. 2007; 7: 412-17.

Yang CM, Luo SF, Hsieh HL, Chi PL, Lin CC, Wu CC, Hsiao LD. Interleukin-1 beta induces ICAM-1 expression enhancing leukocyte adhesion in human rheumatoid arthritis synovial fibroblasts: Involvement of ERK, JNK, AP-1, and NF kappa B. J Cell Physiol. 2010; 224: 516-26. 